
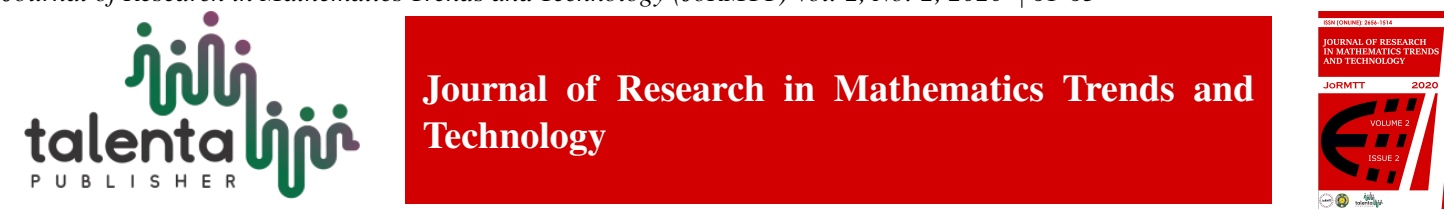

\title{
Another Proof of An Uncountability Real Numbers Set
}

\section{Ofie ${ }^{1}$ and E. Herawati ${ }^{*}$}

${ }^{1}$ Department of Mathematics, Institut Teknologi Bandung, Bandung, 40132, Indonesia

${ }^{2}$ Department of Mathematics, Universitas Sumatera Utara, Medan, 20155, Indonesia

\begin{abstract}
The diagonalization argument is one way that researchers use to prove the set of real numbers is uncountable. In the present paper, we prove the same thing by using the supremum property in the set of real numbers.

Keywords: Diagonalization Argument, Set of Real Numbers, Supremum, Uncountable Set.

Abstrak. Argumen diagonalisasi merupakan salah satu cara yang digunakan para peneliti untuk membuktikan himpunan bilangan real tidak terhitung. Pada paper ini, dibuktikan hal yang sama dengan menggunakan sifat supremum pada himpunan bilangan real.
\end{abstract}

Kata Kunci: Argumen Diagonalisasi, Himpunan Bilangan Real, Supremum, Himpunan Tidak Terhitung.

Received 02 August 2020 | Revised 26 August 2020 | Accepted 29 September 2020

\section{Introduction}

Any real number can be determined by a possibility infinite decimal representation. The uncountability real numbers can be proven by statement that the integer number set and the real number set cannot put into one-to-one correspondence. That we denote the positive integer real numbers by $\mathbb{N}$ and the real numbers by $\mathbb{R}$. The positive integer real number is also called natural number. It is impossible to create an injective function $f: \mathbb{R} \rightarrow \mathbb{N}$. Cantor [1] prove it by using Bolzano-Weierstrass Theorem. In [2] he proved it again later using argument diagonal called Cantor diagonal argument or Cantor diagonal. He proved that there exists "larger" uncountabily infinite set than the countability infinite set of integers. Gray in [3] using Cantor method lead to computer program to determine the transcendental number as $e$ or $\pi$.

In this paper, we also prove the real number set is uncountable use the Cantor Diagonalization, but concentrate on the non-denumerable proof. To do that, we using the supremum property in $\mathbb{R}$, that is for every non-empty subset in $\mathbb{R}$ with an upper bound, there exists a least upper bound, called supremum. The consequence of this property is subset has greatest lower bound, called infimum. The basic concepts such as supremum, uncountable and denumerable can be find in [4].

*Corresponding author at: Department of Mathematics, Universitas Sumatera Utara, Medan, 20155, Indonesia

E-mail address: elvina@usu.ac.id 


\section{Main Results}

In this section, we will look another prove of an uncountable set for the set which is a collection of all real numbers.

Theorem. The real number sets is uncountable.

Proof. We prove by a contradiction ways. Suppose the real number set $\mathbb{R}$ is denumerable, then there exists a bijective function $f: \mathbb{N} \rightarrow \mathbb{R}$. We give the following two real sequences recursively defined by

$$
\begin{aligned}
x_{1} & =f(1) \\
y_{1} & =f\left(\min \left\{n \in \mathbb{N} \mid x_{1}<f(n)\right\}\right) \\
x_{n+1} & =f\left(\min \left\{n \in \mathbb{N} \mid x_{n}<f(n)<y_{n}\right\}\right) \\
y_{n+1} & =f\left(\min \left\{n \in \mathbb{N} \mid x_{n+1}<f(n)<y_{n}\right\}\right) .
\end{aligned}
$$

Then for every $n \in \mathbb{N}$, we get

$$
x_{n}<x_{n+1}<y_{n+1}<y_{n} .
$$

We will show that $x_{n}<y_{m}$ for every $n, m$ in $\mathbb{N}$. Suppose there exists $n_{0}, m_{0}$ in $\mathbb{N}$ such that $x_{n_{0}} \geq y_{m_{0}}$. Since $x_{n}<y_{n}$ for every natural number $n$, it follow that for $n_{0}<m_{0}$ or $n_{0}>m_{0}$

(i) if $n_{0}<m_{0}$, then $x_{n_{0}}<x_{m_{0}}<y_{m_{0}}$. Its contradicts the fact that $x_{n_{0}} \geq y_{m_{0}}$.

(ii) if $m_{0}<n_{0}$, then $x_{m_{0}}<x_{n_{0}}<y_{n_{0}}<y_{m_{0}}$. It is a contradiction with $x_{n_{0}} \geq y_{m_{0}}$.

Therefore

$$
x_{n}<y_{m} \quad \forall n, m \in \mathbb{N}
$$

For every $n \in \mathbb{N}$, we create the set

$$
A=\left\{y_{m} \mid x_{n}<y_{m} \quad \forall m \in \mathbb{N}\right\}
$$

then we get the following conditions.

(i) $A \neq \emptyset$.

(ii) $A$ is a lower bounded set in $\mathbb{R}$ by $x_{n}$ for every $n \in \mathbb{N}$.

By the greatest lower bound property, there exists $a_{*}=\inf A$ in $\mathbb{R}$ for every natural number $m$.

We will show for every $n \in \mathbb{N}$ implies $x_{n}<a_{*}$. Suppose there exists $n_{0} \in \mathbb{N}$ such that $a_{*} \leq x_{n_{0}}$, then $a_{*} \leq x_{n_{0}}<x_{n_{0}+1}$. By the definition of infimum, there exists $m_{0} \in \mathbb{N}$ such that $a_{*}<y_{m_{0}}<x_{n_{0}+1}$. This is contradiction with Eq. (1). Therefore, we have

$$
x_{n}<a_{*}<y_{m} \quad \forall n, m \in \mathbb{N}
$$

Furthermore, since $f$ is a surjective function, we know that there exists $k \in \mathbb{N}$ such that $f(k)=a_{*}$. By the definition of

$$
y_{m}=f\left(\inf \left\{m \in \mathbb{N} \mid x_{m+1}<f(m)<y_{m}\right\}\right) .
$$


Then for every $m \in \mathbb{N}$, there exists $\dot{\gamma}_{m} \in \mathbb{N}$ such that $y_{m}=f\left(\dot{\gamma}_{m}\right)$. So

$$
y_{m}=f\left(\dot{\gamma}_{m}\right)=f\left(\inf \left\{m \in \mathbb{N} \mid x_{m+1}<f(m)<y_{m}\right\}\right),
$$

where $\dot{\gamma}_{m}=\inf \left\{m \in \mathbb{N} \mid x_{m+1}<f(m)<y_{m}\right\}$ and we also have

$$
x_{m+1}<a_{*}=f(k)<y_{m} .
$$

Therefore $k \leq \dot{\gamma}_{m}$.

By the similar argument, we note that

$$
x_{m}<x_{m+1}<f\left(\dot{\gamma}_{m+1}\right)=y_{m+1}<y_{m},
$$

then $\dot{\gamma}_{m+1} \leq \dot{\gamma}_{m}$. But since

$$
y_{m+1}=f\left(\dot{\gamma}_{m+1}\right)<y_{m}=f\left(\dot{\gamma}_{m}\right)
$$

and $f$ is an injective function, therefore $\dot{\gamma}_{m+1} \neq \dot{\gamma}_{m}$. Thus,

$$
\dot{\gamma}_{m+1}<k<\dot{\gamma}_{m} \quad \forall m \in \mathbb{N}
$$

In this case, $k<\infty, 1 \geq \dot{\gamma}_{1}$ and $\dot{\gamma}_{m+1}<\dot{\gamma}_{m}+1$ for every $m \in \mathbb{N}$, then for every $k>m$ we get

$$
\dot{\gamma}_{m}<\dot{\gamma}_{m-1}+1<\dot{\gamma}_{m-2}+2<\cdots<\dot{\gamma}_{1}+m-1 \leq m<k
$$

which is contradiction with Eq. (2). Therefore, $\mathbb{R}$ is non-denumerable.

\section{REFERENCES}

[1] G. Cantor, "Ueber eine elementare fruae der manniqfaltiokeitslehre," Jahresbericht der Deutschen Mathematiker-Vereiniqunq, vol. 1, pp. 75-78, 1891.

[2] R. Smullyan, Diagonalization and Self-Reference. Oxford Univ. Press, 1994.

[3] R. Gray, "Georg cantor and transcendental numbers," American Mathematical Monthly, vol. 101, no. 9, pp. 819-832, 1994. [Online]. Available: https://www.jstor.org/stable/2975129? origin $=$ crossref $\&$ seq $=1$

[4] W. Rudin, Principles of Mathematical Analysis, 3rd ed. New York: McGraw-Hill, 1976. 